NONMETALLIC INCLUSIONS IN JBK-75 STAINLESS STEEL

\author{
A. W. Brewer \\ R. W. Krenzer \\ J. H. Doyle \\ D. H. Riefenberg
}

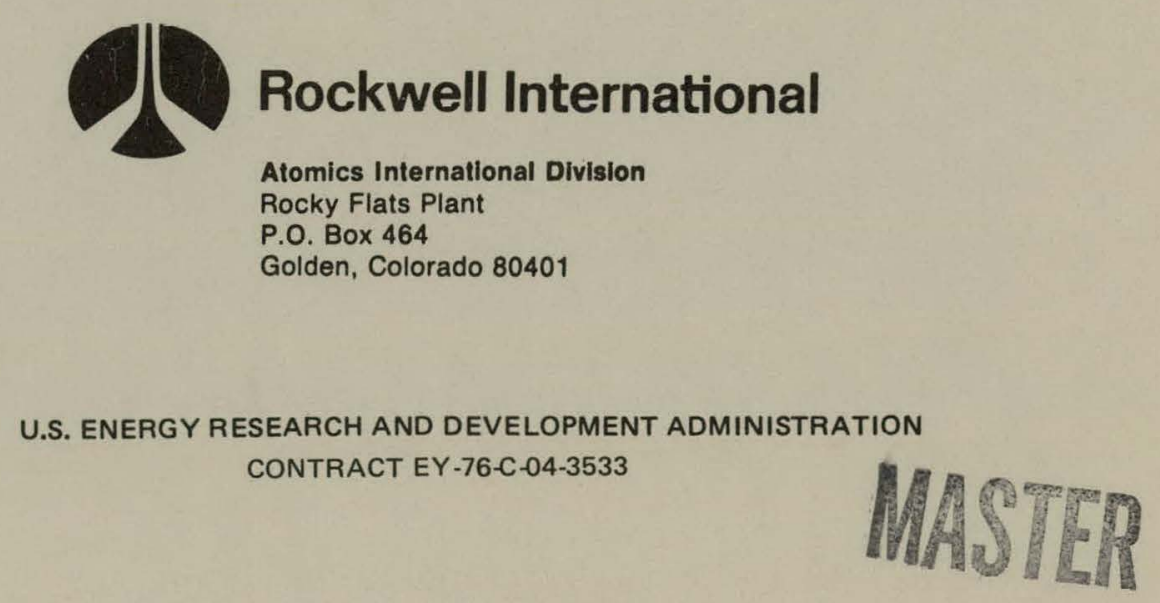




\section{DISCLAIMER}

This report was prepared as an account of work sponsored by an agency of the United States Government. Neither the United States Government nor any agency Thereof, nor any of their employees, makes any warranty, express or implied, or assumes any legal liability or responsibility for the accuracy, completeness, or usefulness of any information, apparatus, product, or process disclosed, or represents that its use would not infringe privately owned rights. Reference herein to any specific commercial product, process, or service by trade name, trademark, manufacturer, or otherwise does not necessarily constitute or imply its endorsement, recommendation, or favoring by the United States Government or any agency thereof. The views and opinions of authors expressed herein do not necessarily state or reflect those of the United States Government or any agency thereof. 


\section{DISCLAIMER}

Portions of this document may be illegible in electronic image products. Images are produced from the best available original document. 


\section{-LEGAL NOTICE}

This report was prepared as an account of work sponsored by the United States Govenument. Neillici the United Statos nor the Energy Research and Development Administration, nor any of their employees, nor any of their contractors, subcontractors, or their employees, makes any warranty, expressed or implied, or assumes any legal liability or responsibility for the accuracy, completeness or usefulness of any information, apparatus, product or process disclosed, or represents that its use would not infringe privately owned rights.

Printed in the United States of America

Available from the

National Technical Information Service

U. S. Department of Commerce

Springfield, Virginia 22161

Price: Printed Copy $\$ 4.50$ Microfiche $\$ 3.00$

Price Is Subject to Change Without Notice 


\title{
NONMETALLIC INCLUSIONS IN JBK-75 STAINLESS STEEL :
}

\author{
A. W. Brewer
}

R. W. Krenzer

J. H. Doyle

D. H. Riefenberg.

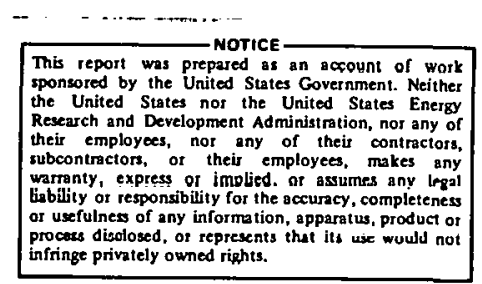

SUBJECT DESCRIPTORS

Stainless Steels

JBK Alloy

Inclusions

Microstructure

This report was prepared as an account of work

sponsored by the United States Covernment. Neilher

Research and Development Administration, nor any or

subcontsployes, nor any of their contractors.

its use would not

infringe privately owned riphts.

ROCKWELL INTERNATIONAL

ATOMICS INTERNATIONAL DIVISION

ROCKY FLATS PLANT

P.O. BOX 484

GOLDEN, COLOAADO 80401

Prepared under Contract EY-76-C-04-3533

for the

Albuquerque Operations Office

U. 8. Energy Research and Development Administration

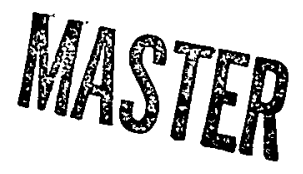


RFP-2536

\section{CONTENTS}

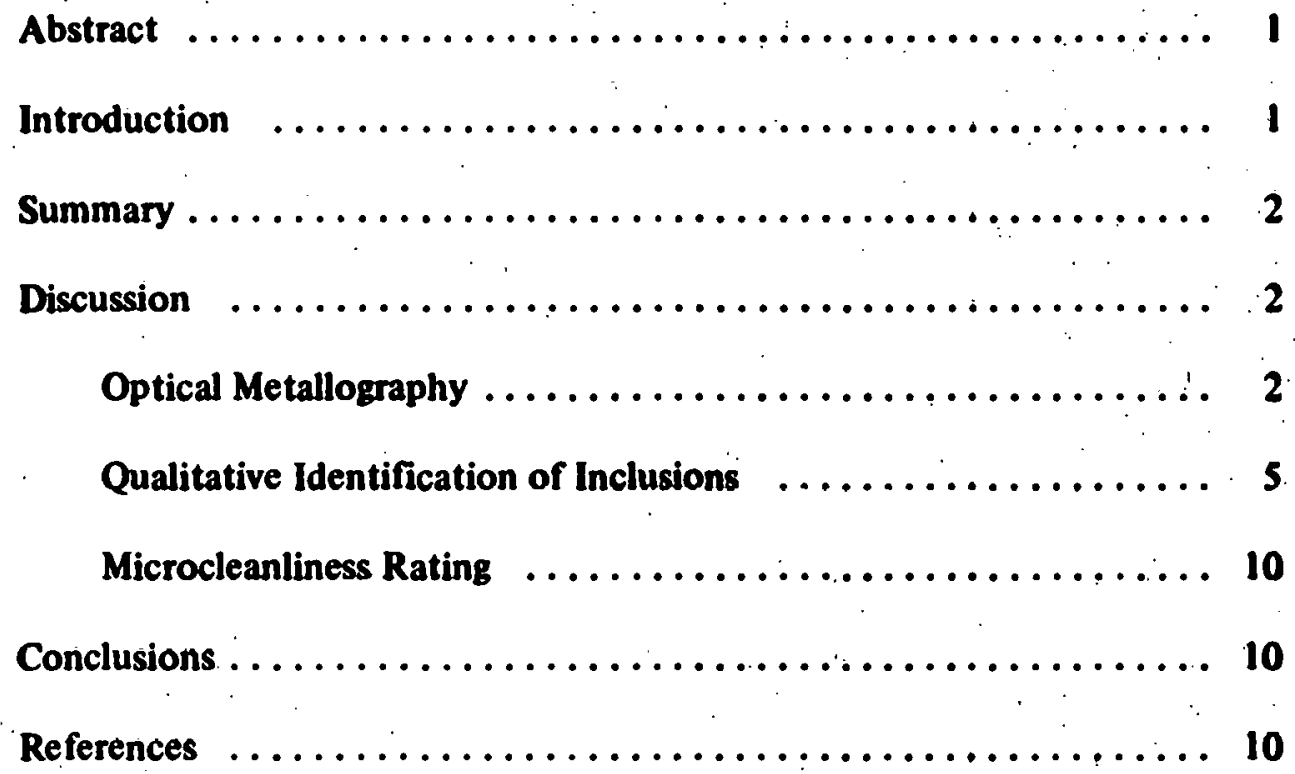




\title{
NONMETALLIC INCLUSIONS IN JBK-75 STAINLESS STEEL
}

\author{
A. W. Brewer, R. W. Krenzer, J. H. Doyle, and D. H. Riefenberg
}

\begin{abstract}
Stainless steel alloys that are chemically complex, such as A- 286 or JBK-75, are designed to improve such high-temperature properties as strength. This is accomplished by precipitating secondary phases during aging. Such multicomponent systems, however, can also produce undesirable phases that are detrimental to forgeability and final mechanical properties. Cast segregation and numerous nonmetallic inclusions can have a degrading influence on the toughness and ductility of the alloy. Several different heats of A-286 and JBK-75 were studied, and titanium carbide and/or molybdenum carbide [( $\mathrm{Ti}, \mathrm{Mo}) \mathrm{C}$ ] plus titanium carbide and/or titanium carbonitride Ti (C,N)-type phases were qualitatively identified as the major nonmetallic constituent in these alloys. The common procedure for rating the microcleanliness of steels does not classify such carbide or carbonitride phases and thus does not provide an appropriate means of controlling in-process inspection. The results of this study are discussed in terms of alternative methods for evaluating the microcleanliness of superalloys.
\end{abstract}

\section{NTRODUCTION}

In stainless steel superalloys such as A-286 or JBK-75, ${ }^{1}$ the occurrence of a variety of nonmetallic and intermetallic inclusions is primarily dependent upon alloy chemistry and processing parameters during melting, ingot breakdown, and metalworking operations such as forging. Conditions that promote precipitation of such phases are difficult to assess in a chemically complex alloy like JBK-75; identification of phases is equally difficult. Microstructural control becomes even more important in processing superalloys because of the large number of possible microconstituents that can have an adverse effect on the mechanical properties of the alloy. Total elimination of undesirable phases is impossible. One can only minimize marcosegregation and precipitation of second phases by proper process control.

Superalloy properties are influenced by all stages of the manufacturing process. This includes one of the most important steps, the initial melting practice. The melting process can have a profound effect on subsequent processing and property response of the material. A common practice in industry is to use a double melting process in which the first step is an air-arc melt (AAM), air-induction melt (AIM), or vacuum-induction melt (VIM). This action is followed by a final step such as vacuum-arc remelting (VAR) or electroslag remelting:(ESR).

Superalloy ingots produced with such: duplex melting generally have improved cleanliness, better homogeneity of the alloy's chemical constituents, and more desirable ingot structure. Proper control of duplex melting results in improved cleanliness by minimizing typical slag constituents such as oxides, silicates, and sulfides. Entrapment of slag inclusions in the solidified alloy can be avoided by employing sophisticated melting techniques; still, numerous nonmetallic inclusions can be found in A-286 and JBK-75. The reason is that these alloys contain strong carbide and nitride formers.

Formation of complex carbide/nitride compounds can have a deleterious effect on mechanical properties of the alloy, and even though their occurrence cannot be completely avoided, the quantity, size, and distribution of these compounds can be controlled by alloy chemistry, melting parameters, and ingot breakdown practice..

The purpose of the present study is to compare the microcleanliness of several A-286 and JBK-75 heats that are melted using different techniques. In addition, typical nonmetallic inclusions in each heat are to be examined optically and with the electron microprobe.

Some method for rating inclusion content in this type of alloy is necessary to maintain a quality standard for acceptance of forging stock. The widely used standard, ASTM-E-45, for determining the inclusion content of steel is not directly applicable to A-286 or JBK-75. The commonly found carbides and carbonitride inclusions in these alloys are not covered in the ASTM-E-45 
TABLE 1. Chemical Analysis of Heat Samples

\begin{tabular}{|c|c|c|c|c|c|c|c|c|c|c|c|c|c|c|c|}
\hline \multirow[b]{2}{*}{ Alloy } & \multirow{2}{*}{$\begin{array}{l}\text { Heat } \\
\text { Number }\end{array}$} & \multirow{2}{*}{$\begin{array}{l}\text { Melting } \\
\text { Practice } \\
\end{array}$} & & \multicolumn{2}{|c|}{$\begin{array}{l}\text { Alloy Elements } \\
\text { (wt \%)* }\end{array}$} & \multirow[b]{2}{*}{ Cr } & \multirow[b]{2}{*}{$\mathbf{v}$} & \multirow[b]{2}{*}{ Mo } & \multirow[b]{2}{*}{ B } & $\rightarrow$ & \multirow[b]{2}{*}{$\mathrm{Ti}$} \\
\hline & & & $N$ & C & $\mathbf{P}$ & s & $\mathrm{Si}$ & $\mathrm{Mn}$ & $\mathrm{Ni}$ & & & & & Al & \\
\hline A-286 & $7490-3$ & AAM/ESR & NA & 0.04 & 0.010 & 0.005 & 0.59 & 1.60 & 24.59 & 15.31 & 0.34 & 1.33 & 0.006 & 0.23 & 2.2 \\
\hline A-286 & $7490-5$ & AAM/VAR & NA & 0.05 & 0.010 & 0.008 & 0.57 & 1.40 & 24.64 & 15.39 & 0.35 & 1.32 & 0.006 & 0.23 & 2.2 \\
\hline JBK-75 & $6225-1$ & AAM/VAR & NA & 0.03 & 0.012 & 0.008 & 0.06 & 0.23 & 30.60 & 14.41 & 0.18 & 1.21 & 0.001 & 0.14 & 1.86 \\
\hline JBK-75 & T6787 & AAM/VAR & 0.0055 & 0.03 & 0.010 & 0.010 & 0.10 & 0.23 & 30.90 & 14.23 & NA & 1.35 & 0.002 & 0.19 & 1.88 \\
\hline JBK-75 & $926^{* *}$ & VIM/ESR & NA & 0.020 & 0.005 & 0.003 & 0.04 & $<0.01$ & 30.85 & 14.45 & 0.30 & 1.28 & $<0.001$ & 0.27 & 2.23 \\
\hline JBK-75 & 927 & VIM/ESR & 0.0036 & 0.024 & 0.004 & 0.002 & 0.03 & .0 .05 & 30.09 & 14.28 & 0.30 & 1.32 & $<0.001$ & 0.26 & 2.12 \\
\hline JBK-75 & $2448^{* *}$ & VIM/ESR & 0.0038 & 0.019 & 0.005 & 0.003 & $<0.01$ & 0.02 & 30.00 & 14.35 & 0.33 & 1.36 & $<0.001$ & 0.31 & 2.18 \\
\hline JBK-75 & SLA-Z $\dagger$ & VIM/VAR & NA & 0.015 & NA & 0.006 & NA & NA & 30.5 & 15.2 & 0.25 & 1.30 & NA & 0.27 & 2.14 \\
\hline
\end{tabular}

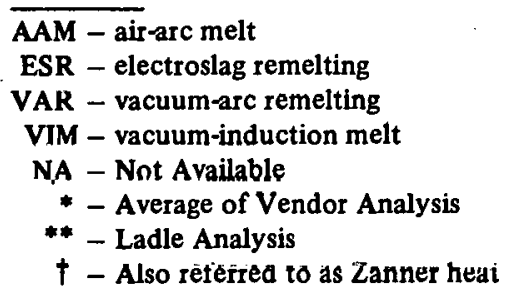

specification. In addition to considering inclusion type, it is important to define a criteria based on distribution of inclusions. A rating system based on specific distributions of carbide-type inclusions would be more meaningful than ASTM-E-45 for superalloys. Photomicrographic standards also should be established that will directly relate to the requirements of a specific application. It is intended that information derived from the study reported here form a historical basis for establishing such a specitication.

\section{SUMMAR Y}

It is practically impossible to eliminate carbide-type inclusions in alloys such as $\mathrm{A}-286$ and $\mathrm{JBK}-1 \mathrm{~S}$. Product quality can be controlled only through proper melting procedures and effective breakdown practice so that such inclusions are sufficiently dispersed throughout the alloy. Thus, the size and distribution of carbide inclusions become an important measure of product quality. A fine, uniform dispersion of inclusions is desirable. Procedures developed by Cameron Iron Works and Ladish would be most appropriate to use as an acceptance criteria in rating microcleanliness of JBK-75 bat stock. The curbide-stuinger array, particularly common to Heat Number 926,927 , and 2448 then could be more ettectively controlled. The sulfide stringers found in these samples are too small to be a factor in rating the microcleannlineșs of the alloy at a magnification of $100 \mathrm{X}$; however, their presence may be a significant factor influencing the mechanical properties of JBK-75.

\section{DISCUSSION}

\section{Optical Metallography}

Samples from two A-286 heats and six JBK-75 heats were examined. JBK-75 is essentially a weldable grade of A-286 but with a higher nickel (Ni) content and reduced amounts of carbon (C), silicon ( $\mathrm{Si}$ ), manganese (Mn), and boron (B) than A-286. The product from two different vendors plus a combination of four different melting practices were represented in the samples. All heats were double melted, which is common practice with superalloys. A chemical analysis of each heat is tabulated in Table 1 . In addition to 


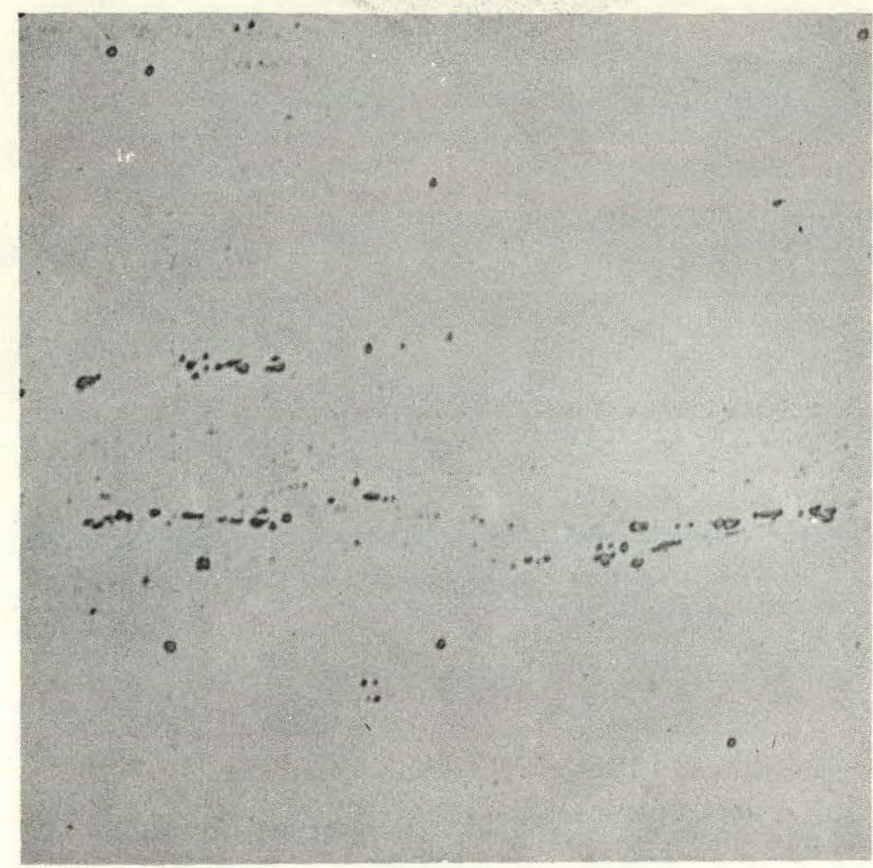

FIGURE 1. Typical Inclusions Found in JBK-75, VIM/ESR, Heat Number 927. 100X

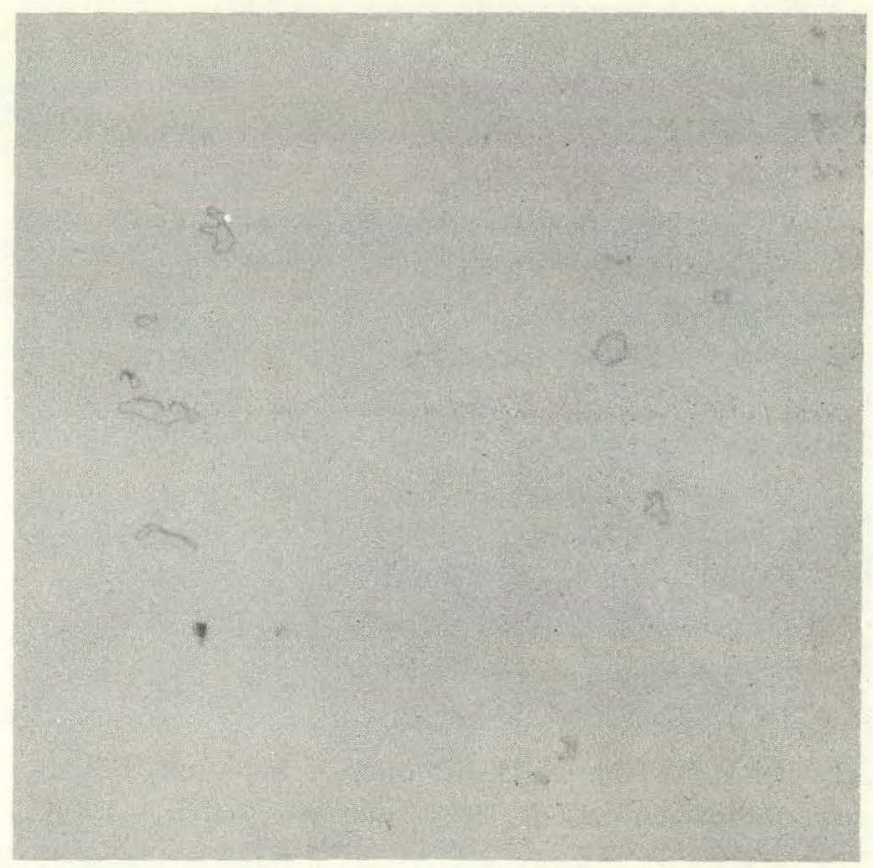

FIGURE 2. Inclusions Found in Heat Number 927 at a Magnification of $400 \mathrm{X}$ determining the types of nonmetallic inclusions in each alloy, it was of interest to examine whether there was any obvious influences of alloy chemistry and melting practice on the type and distribution of inclusions in each case. Samples from each heat were examine with the optical microscope, electron microprobe, and the scanning electron microscope.

Representative regions of each heat were examined optically to compare the size and distribution of inclusions. By far, the worst examples of abundant inclusions were Heat Numbers 926, 927, and 2448. All of these JBK-75 heats were VIM/ESR from the same vendor. An example of the carbide-type stringers present in those heats is shown in Figures 1 and 2. By comparison, A-286, Heat Number 7490-3, which was AAM/ESR, had a much finer, uniform dispersion of inclusions. These inclusions are shown in Figure 3.

If alloy chemistry played a role, one would expect the JBK-75 heats to be cleaner since JBK-75 has lower impurity levels than A-286. This is not the case, however, so some other factor must be a major contributor. Two possibilities exist. First, although ESR melting is considered an excellent practice for providing inclusion-free material, this assumes optimum control of the process. Heats 927 and 7490-3 were supplied by different vendors and illustrate a possible sensitivity of control during ESR melting. Secondly, although these samples were taken from bar stock of approximately the same size, in the range of 4 to 5 inches in diameter, the ingot breakdown schedule of each vendor varied greatly. Breakdown temperatures and amount of deformation at specific temperatures will have a significant influence on inclusion distribution in the final bar product. Specific breakdown parameters for these heats are unknown. This points out the need for closer control of ingot breakdown in an application where final product quality can be significantly affected. It is impossible in the present case to single out the effects of ESR melting and breakdown practice on the inclusion content of the bar stock.

Each of the VAR heats - 7490-5, 6225-1, T6787, and SLA-Z-are much cleaner; i.e., they have fewer 


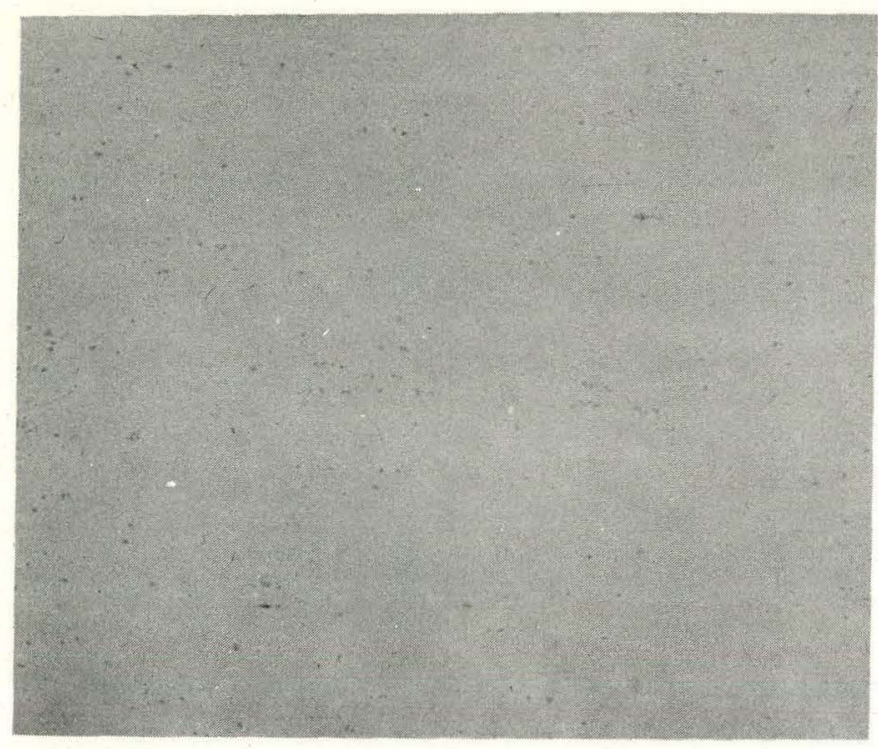

FIfIIRF 3. Typical Distribution of Inclusions Found in A-286, AAM/ESR, Heat Number 7490-3. 100X

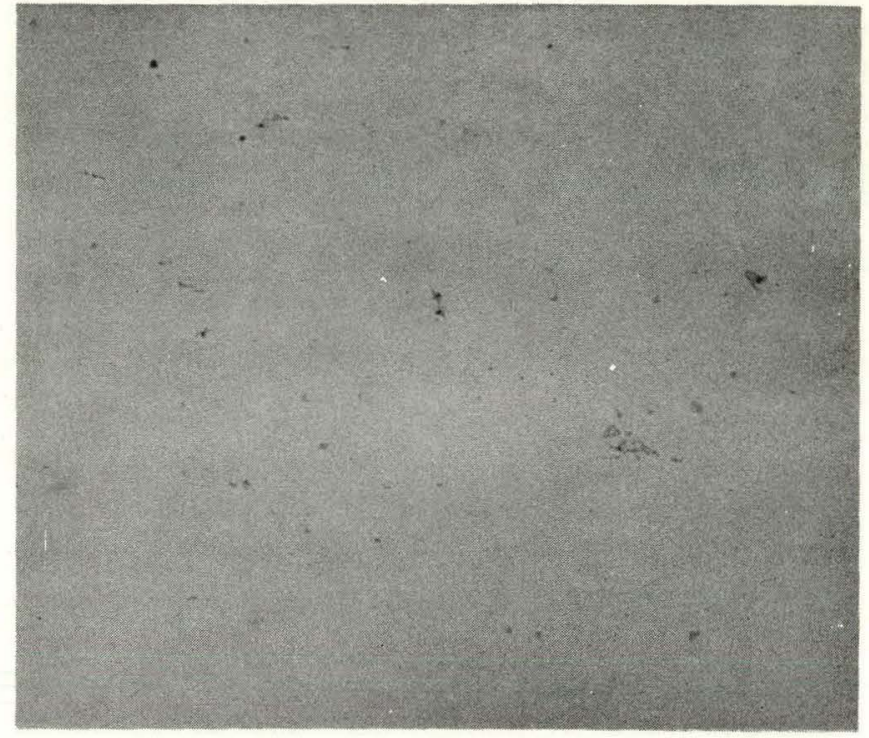

FIGURE 4. Typical Distribution of Inclusions Found in A-286, AAM/VAR, Heat Number 7490-5. 100X

FIGURE 5. Inclusions from Heat Number SLA-Z, JBK-75, VIM/VAR, Exampling an Acceptable Form of Inclusion.

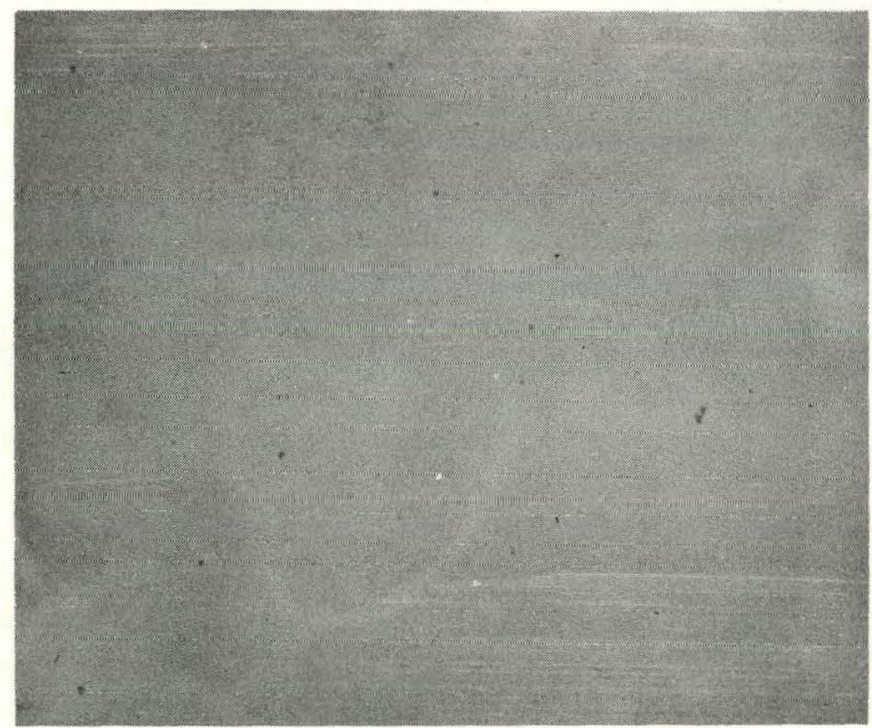

inclusions with a reduction in carbide-type stringers. Figure 4 shows a typical distribution of inclusions in AAM/VAR A-286. The size and distribution of inclusions in the AAM/VAR and AAM/ESR heats are quite different. Heat SLA-Z (Figure 5) is an example of what can be achieved with proper control of the melting operation. This VIM/VAR heat, which had the fewest inclusions of any heat studied, differed from the other heats in two aspects. The heat size of 500 pounds was smaller than production quantities of 3000 to 8000 pounds. Also, mischmetal was added to the melt because of mischmetal's deoxidation potential. The rare-earth compound, mischmetal, changes the 
chemical composition of stable inclusions that form during solidification, and additions of rareearth metals are known to improve mechanical properties of certain steels. However, the use of rare-earth metals is not a common practice in industry, possibly because of a cost factor.

Optical examination of the limited number of heats available for this study showed that VIM/VAR product would be superior for applications requiring minimum inclusion contents. The bar stock quality is most likely dependent upon the capabilities of the specific vendor. The inclusion content for each of the three VIM/ESR JBK-75 heats studied were below average quality when compared to A-286 or JBK-75 AAM/VAR. Heavy carbide-type were common to all VIM/ESR JBK-75 heats, and such stringers are detrimental to forgeability and to other mechanical properties of the final product.

\section{Qualitative Identification of Inclusions}

Samples from five heats were examined with the electron microprobe and the scanning electron microscope. The intent of this part of the study was to determine the major types of nonmetallic inclusions in A-286 and JBK-75. Carbides, oxides, silicates, and sulfides are examples of the general type of description provided. Specific quantitative identification of each inclusion type was not attempted in this study.

The electron $\mathrm{m}$ icroprobe has both energy nondispersive and crystal spectrometer X-ray detectors. The energy nondispersive detector was used whenever possible. To determine molybdenum, niobium, and sulfur, however, the crystal spectrometer had to be used because of the close proximity of these elements' X-ray fluorescence lines. The PET (pentaery thritol) crystal used in the spectrometer readily resolves the molybdenum (Mo) L $a$ line from the sulfur (S) Ka line. The light element spectrometer detects carbon (C) well but works poorly for nitrogen $(\mathrm{N})$. Nitrogen analysis was run on one sample using a new spectrometer on a scanning electron microscope. The inclusions containing nitrogen also had trace amounts of carbon. From this difference in carbon content, it is assumed in this study that inclusions with trace amounts of carbon are most likely carbonitrides with significant levels of nitrogen. More work is needed on

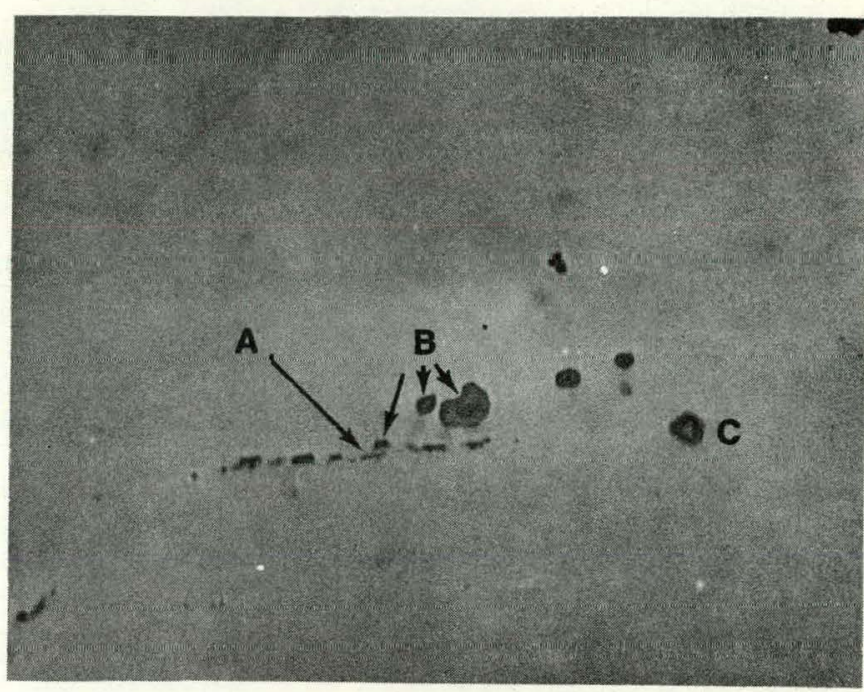

Legend

A. Titanium, sulfur, and carbon - gray.

B. Titanium, carbon with molybdenum, niobium, silicon - gray with black line around particle.

C. Titanium, carbon nitrogen - Light gray with black line around particle and is inside the titanium carbide.

FIGURE 6. Optical Micrograph Showing Three Types of In clusions in A-286, AAM/VAR, Heat Number 7490-5. 800X

the relative amounts of carbon and nitrogen in various inclusions.

Three types of inclusions were found in this study. Titanium carbides with molybdenum (Mo), silicon ( $\mathrm{Si})$, and in some cases niobium ( $\mathrm{Nb}$ ), are the most prevalent and largest inclusion type and are usually angular or in a stringer array. Straight-sided or equiaxed inclusions are high in titanium (Ti) and nitrogen and low in carbon, most likely $\mathrm{Ti}(\mathrm{C}, \mathrm{N})$. These inclusions commonly occur inside titanium carbide particles and optically appear lighter in color than the titanium carbide. Narrow stringers of small inclusions were found to be high in titanium with a low concentration of sulfur and a trace of carbon. No analysis was made for nitrogen on these narrow stringers. Optically, the sulfide inclusions appear gray and are somewhat softer as they do not stand out in relief in a mechanically polished surface. The carbides and carbonitrides are hard and stand out in relief after mechanical polishing. The carbides appear gray while the carbonitrides are lighter in color (see Figure 6). 
TABLE 2. Electron-Microprobe Analysis of Inclusions

Legend

$\mathbf{M}=$ Major Component, $\mathbf{H}=$ High Concentration, $\mathbf{L}=$ Low Concentration,

$\mathrm{T}=$ Trace Amounts, $\mathrm{P}=$ Probable, based on work from sample.

\begin{tabular}{|c|c|c|c|c|c|c|c|c|c|c|}
\hline Heat Number & Shape & Est. \% of Total & $\mathrm{Ti}$ & c & $\mathbf{N}$ & Mo & $\underline{\mathrm{Si}}$ & s & $\mathrm{Nb}$ & $\underline{w}$ \\
\hline \multirow[t]{3}{*}{$\begin{array}{l}7490-3^{*} \\
\text { and } 7490-5^{*}\end{array}$} & $\left.\begin{array}{l}\text { Angular } \\
\text { Stringer }\end{array}\right\}$ & 70 & $\begin{array}{l}M \\
M\end{array}$ & $\begin{array}{l}\text { L } \\
\text { L }\end{array}$ & & $\begin{array}{l}\text { L } \\
\text { H }\end{array}$ & $\begin{array}{l}\text { L } \\
\text { L }\end{array}$ & & $\begin{array}{l}\mathrm{L} \\
\mathrm{H}\end{array}$ & $\mathbf{T}$ \\
\hline & Equiaxed & 20 & M & $T$ & $\mathbf{P}$ & & & & & \\
\hline & Narrow Stringer & 10 & M & $T$ & & & & L & & \\
\hline \multirow[t]{3}{*}{$2448^{* *}$} & Stringer & 15 & M & L & & L & L & & & \\
\hline & Equiaxed & 80 & M & $\mathbf{T}$ & $\mathbf{P}$ & & & & & \\
\hline & Narrow Stringer & 5 & M & $T$ & & & & $\mathbf{L}$ & & \\
\hline \multirow[t]{3}{*}{$927 * *$} & $\left.\begin{array}{l}\text { Angular } \\
\text { Stringer }\end{array}\right\}$ & 45 & $\begin{array}{l}M \\
M\end{array}$ & $\begin{array}{l}\text { L } \\
\text { L }\end{array}$ & & $\begin{array}{l}\text { L } \\
\text { L }\end{array}$ & $\begin{array}{l}\text { L } \\
\text { L }\end{array}$ & & & \\
\hline & Equiaxed & 50 & M & $\mathrm{T}$ & $\mathbf{P}$ & & & & & \\
\hline & Narrow Stringer & 5 & M & $\mathrm{T}$ & & $\mathbf{L}$ & & L & & \\
\hline \multirow[t]{3}{*}{$926 * *$} & $\left.\begin{array}{l}\text { Angular } \\
\text { Stringer }\end{array}\right\}$ & 75 & $\begin{array}{l}M \\
M\end{array}$ & $\begin{array}{l}\mathrm{L} \\
\mathrm{L}\end{array}$ & & $\begin{array}{l}\mathbf{L} \\
\mathbf{L}\end{array}$ & $\begin{array}{l}\text { L } \\
\text { L }\end{array}$ & & & \\
\hline & Equiaxed & 20 & M & $\mathrm{T}$ & $\mathbf{P}$ & & & & & \\
\hline & Narrow Stringer & 5 & M & $\mathrm{T}$ & & & & L & & \\
\hline \multirow{3}{*}{$\begin{array}{l}\text { SLA-Z** } \\
\text { (also called Zanner) }\end{array}$} & Angular & 45 & M & L & & L & $\mathbf{L}$ & & & \\
\hline & Equiaxed & 50 & M & $T$ & $\mathbf{P}$ & & & & & \\
\hline & Narrow Stringes & 5 & M & $T$ & & & & I. & & \\
\hline
\end{tabular}

A summary of electron-microprobe results is given in Table 2. The relative inclusion concentrations were approximated by visual observation. In all cases, titanium and molybdenum were associated with inclusions found in each of the five heats. Both of these elements are potent carbide formers. No oxide or silicate inclusions were found. Niobium was found only in the A-286 samples, not in JBK-75. Although niobium is not an intentional alloy addition of A-286, contamination from superalloy scrap used to melt the A-286 is a possible source. Also, silicon ( $\mathrm{Si}$ ) was mainly prevalent in A-286, where the silicon content is at least an order of magnitude higher than in JBK-75. Tungsten was found in only one isolated case. Sulfide inclusions represented a small volume fraction of the inclusions present.
Figure 7 illustrates the three types of inclusions found in Heat 7490-3. The large angular or blocky inclusions are primarily $\mathrm{Ti}$ with smaller amounts of $\mathrm{Nb}, \mathrm{Mo}$, and Si. This phase is most likely a carbide or carbonitride. The linear inclusions ase similar to the larger blocky phase but have higher concentrations of Mo and Nb. Similar inclusions were found in Heat 7490-5 (see Figure 8). The blocky particles in the form of a stringer are primarily $\mathrm{Ti}$ with Mo and C. Trace amounts of $\mathrm{Nb}, \mathrm{Si}$, and tungsten (W) also were found in these stringers. The carbon count rate was relatively high in these particles. The large single particle was primarily $\mathrm{Ti}$, and the carbon content of this particle was much lower than the phases in the stringer array. This indicated a probable carbonitride. 


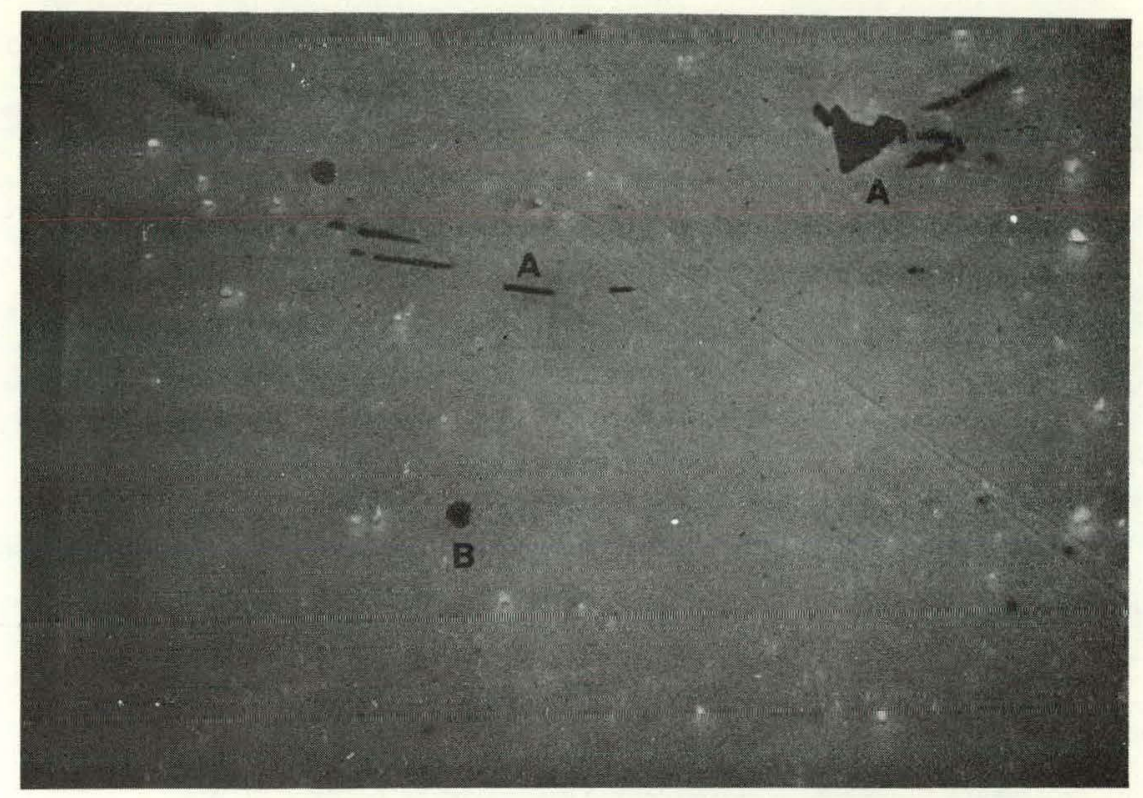

FIGURE 7. Scanning Electron Micrograph of A-286, AAM/ESR, Heat Number 7490-3, Showing Typical Inclusions of (A) Titanium, Molybdenum, and Niobium, and (B) Titanium Carbide and/or Titanium Carbonitride. 500X

FIGURE 8. Scanning Electron Micrograph of A-286, AAM/VAR, Heat Number 7490-5, Showing Two Types of Inclusions: (A) Titanium and Molybdenum, and (B) Titanium Carbide and/or Titanium Carbonitride. 500X

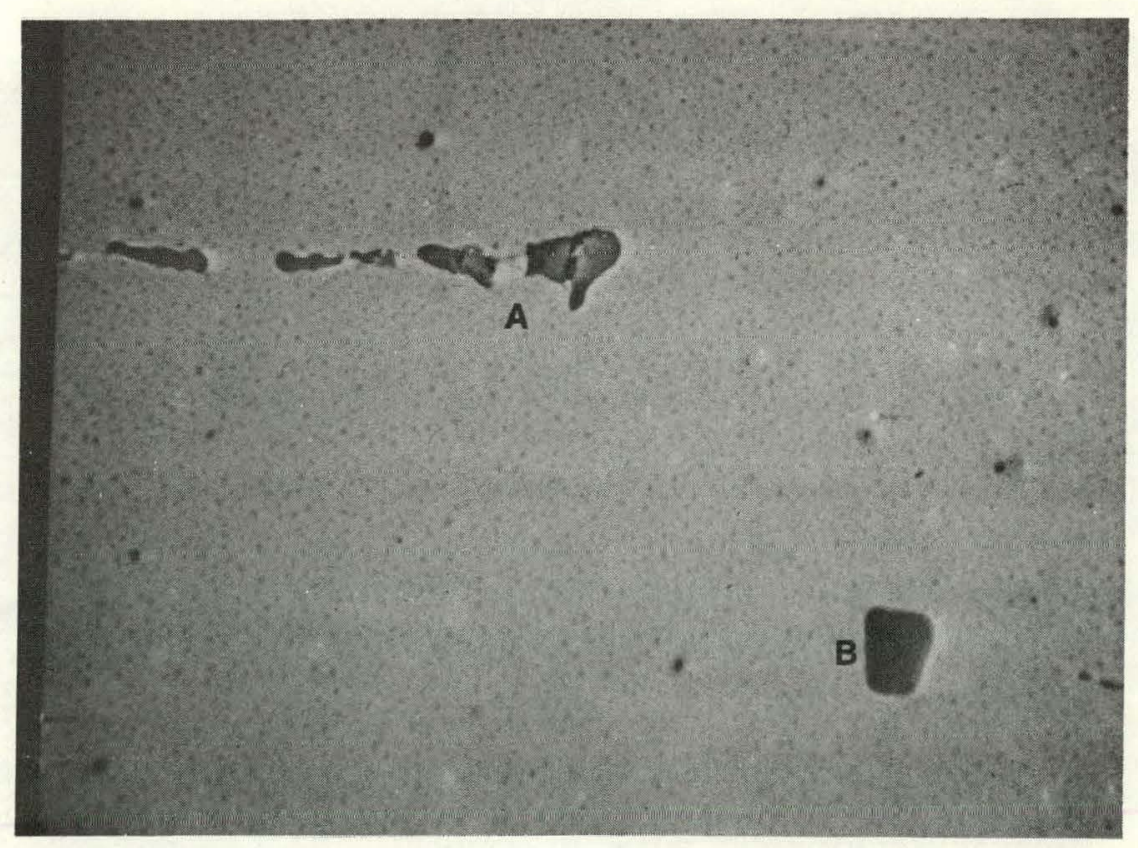


RFP-2536

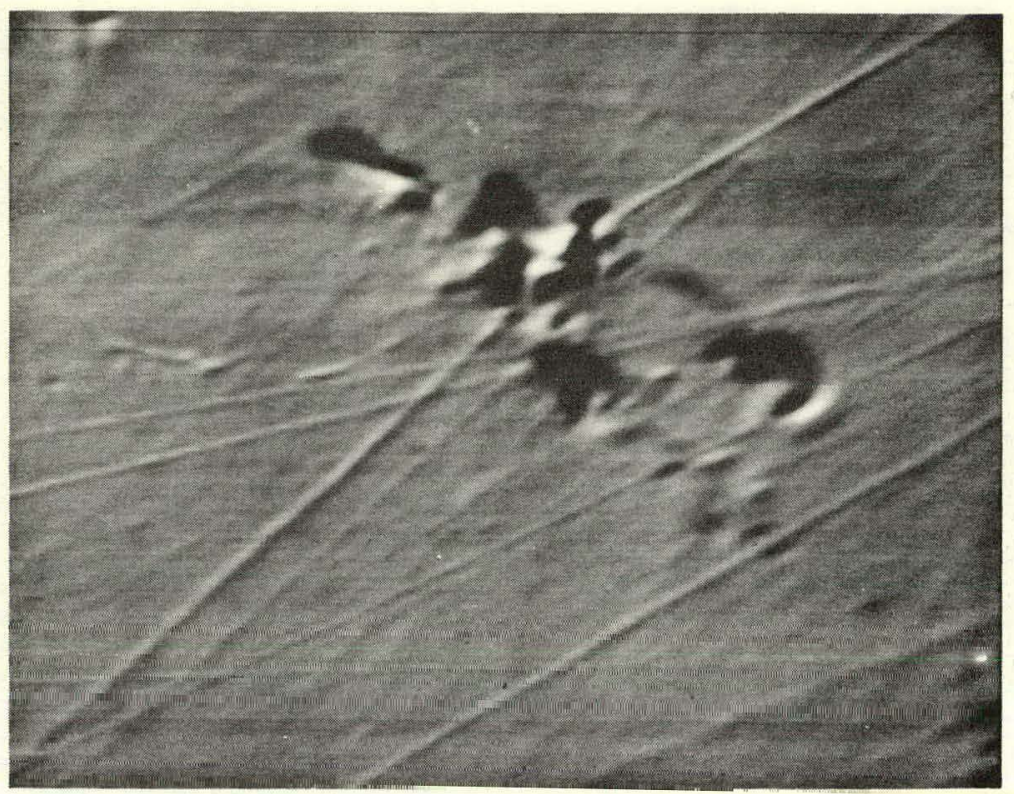

FIGURE 9. Back Scatter Image of Titanium, Molybdenum, and Sulfur Concentrations in Inclusions Found in JBK-75, VIM/ESR, Heat Number 927. 1000X

FIGURE 10. Dispersive X-ray Images of Tilanium $\mathrm{K} \alpha$ Concentrations in Inclusions Found in JBK-75, VIM/ESR, Heat Number 927 (See Figure 9)

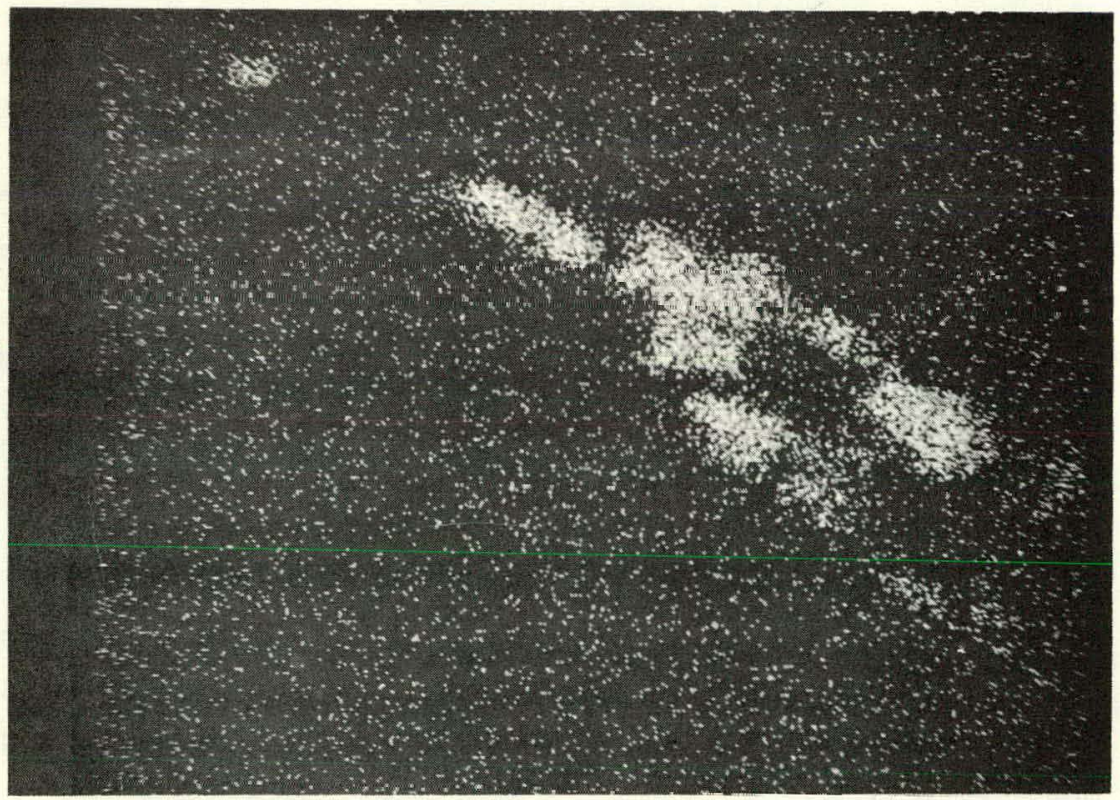




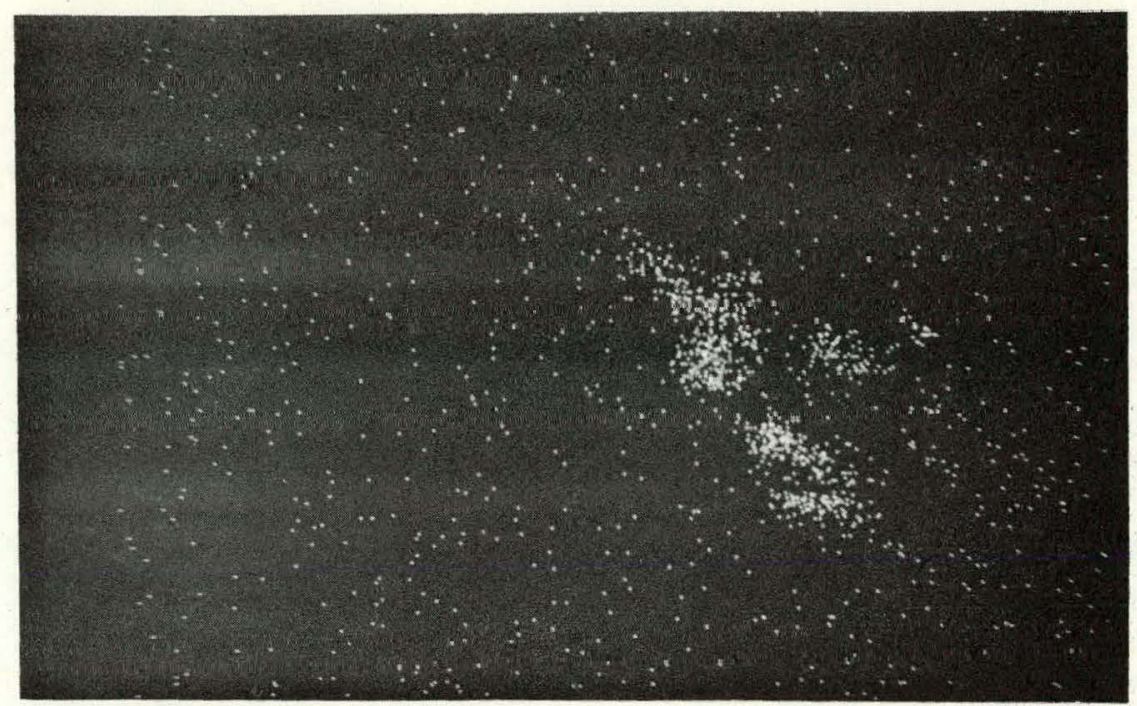

FIGURE 11. Dispersive X-ray Images of Sulfur K $\alpha$ Concentrations in Inclusions Found in JBK-75, VIM/ESR, Heat Number 927 (See Figure 9)

FIGURE 12. Dispersive X-ray Images of Molybdenum L $\alpha$ Concentrations in Inclusions Found in JBK-75, VIM/ESR, Heat Number 927 (See Figure 9)

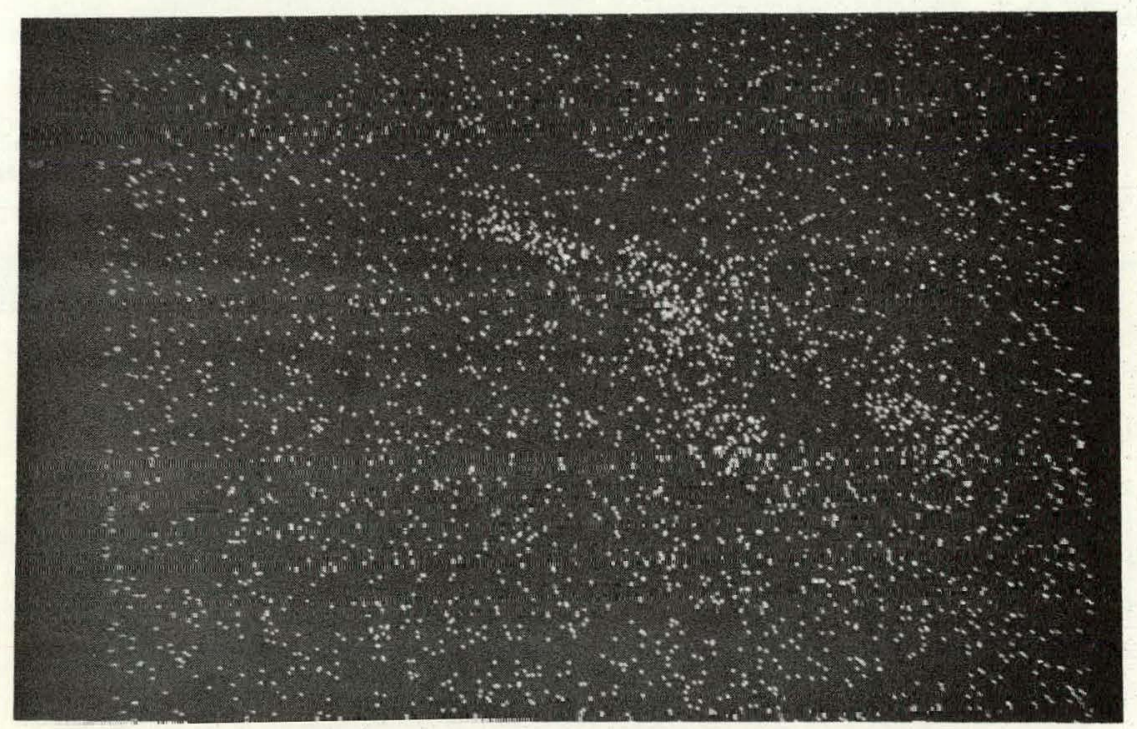

Figure 9 shows a back scatter image of a cluster of inclusions in Heat Number 927; Figures 10-12 show the concentration raster scan of $\mathrm{Ti}, \mathrm{Mo}$, and $\mathrm{S}$ in the inclusions. The three elements' association in the inclusions is readily seen; however, the trace amounts of Mo are difficult to resolve. Trace arriounts of carbon were found with this type of inclusion, and it is possible that the inclusions are a titanium-rich carbosulfide.

Microprobe results showed that in the A-286 and JBK-75 samples investigated, the major type of nonmetallic inclusion was some form of a carbide and/or carbonitride. In addition, limited quantities 
of small sulfide stringers were found. All of the metallic elements identified are carbide formers. No oxide or silicate phases were found.

\section{Microcleanliness Rating}

The ASTM E-45 specification for determining the inclusion content of steel does nut consider carbide-type inclusions; consequently, some alternative means of rating the size and distribution of carbides is necessary. It is common practice in industry to write an internal specification based on previous experience with microcleanliness in superalloys. One such procedure has been developed by Cameron Iron Works and has been submitted to ASTM for approval as a standard specification for wrought high-temperature alloys. ${ }^{2}$ Approximately 2000 microspecimens were examined by Cameron Iron Works to establish a quantitative rating system based on inclusion distribution. This distribution is categorized as stringers, clusters, chains, and background. The Ladish Company also has developed a similar procedure for rating stringer-, network-, and cluster-type distributions within a 0.030 - hy 0.040 -inch field of view at a magnification of $100 \mathrm{X} .^{3}$

\section{CONCLUSIONS}

1. Three types of inclusions were found in this study: a titanium carbide-lype phase with molybdenum, silicon, and some cases niobium; a titanium carbide and/or titanium carbonitride Ti (C,N)-type phase; and small sulfide stringers with titanium and trace amounts of carbon. Since nitrogen analysis was difficult to obtain, it may be that the phase identified as a carbide had trace amounts of nitrogen. More work is needed toward determining the relative amounts of carbon and nitrogen in each of the phases. There apparently are two types of carbonitrides; one is a carbon-rich phase, and the other is a nitrogen-rich phase.

2. The major nonmetallic inclusion found in these A-286 and JBK-75 samples was the titaniumrich carbide or carbonitride phase. Only minor amounts of the sulfide phase were found.
3. No oxide or silicate inclusions were found in this study.

4. There were no obvious correlations between alloy chemistry and inclusion content in the samples investigated. The A-286 samples, in general, had lower inclusion contents than JBK-75, even though impurity levels are higher in A-286.

5. Titanium and molybdenum were the major metallic elements associated with inclusions in all heats studied.

6. The three VIM/FSR JBK-75 heats possessed hcavy carbide-type stringers. Lack of microclcanliness in these heats is possibly the result of improper controls during the melting operation.

7. Both the AAM/VAR and VIM/VAR heats showed a finer, more uniform dispersion of nonmetallic inclusions. This initial experience would favor VIM/VAR melting practice.

8. Industry generally relies on internal specifications to rate the microcleanliness of superalloys. Having some measure of the size and distribution of carbide-type inclusions is most important in controlling the mechanical properties of wrought product.

\section{REFERENCES}

1. J. A. Brooks and R. W. Krenzer. Weldable, Age Hurdenable, Austenitic Stainless Steel. U. S. Patent 3,895,939. July 22, 1975.

2. D. Nail. Cameron Iron Works, Houston, Texas. Private communications. February 1, 1977.

3. R. P. Daykin and A. J. DeKidder. "Preliminary Working of Superalloys." SuperalloysProcessing, Proceedings of The Second International Conference. Page F-2. Metals and Ceramics Information Center, Battelle Columbus Laboratories, Columbus, Ohio. September 1972. 